\title{
Traffic Performance of Arterial Highways and Driver Routing Characteristics during a Freeway Detour
}
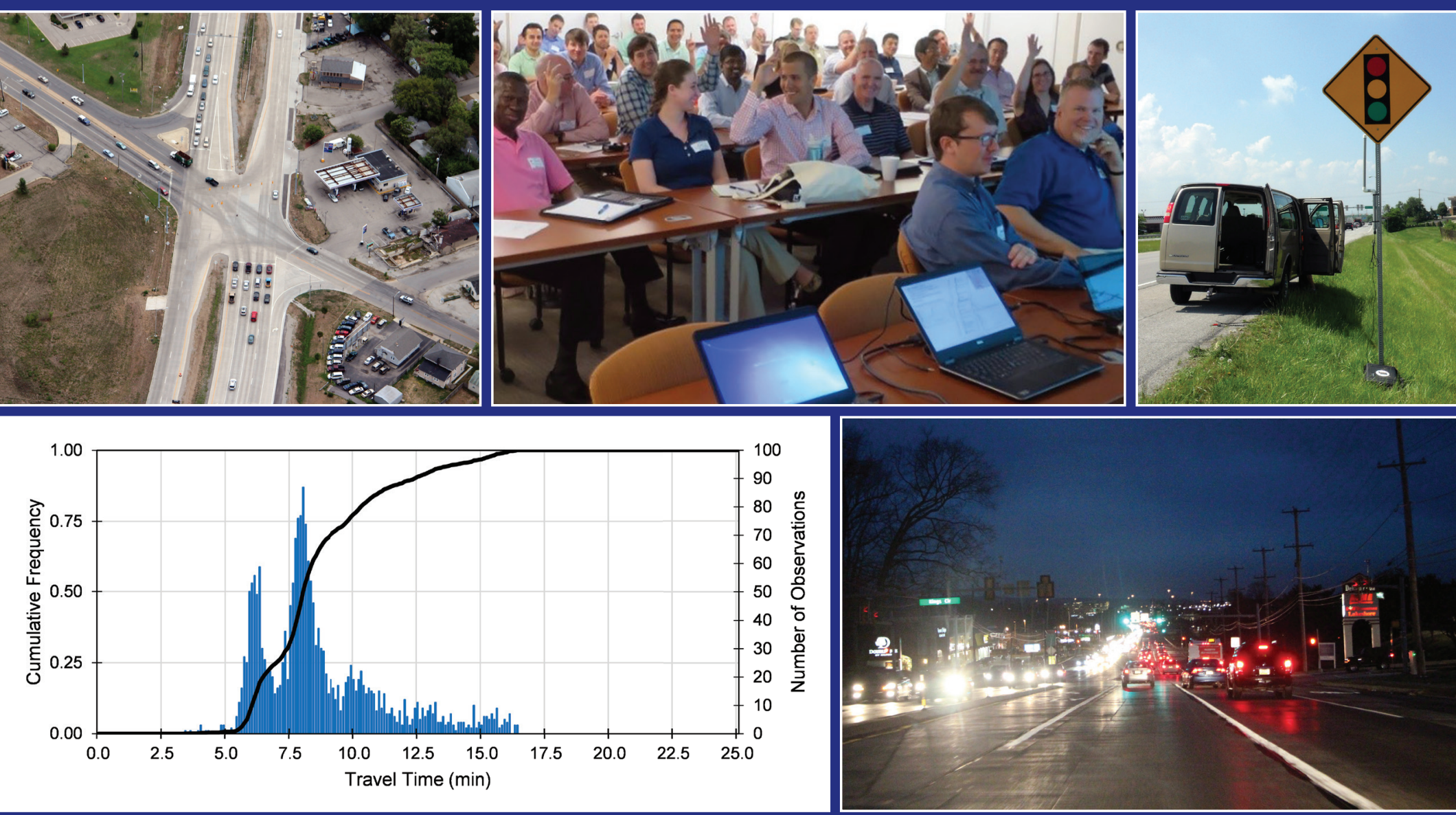

Christopher M. Day, Steven M. Lavrenz, Howell Li, Darcy M. Bullock 


\title{
Traffic Performance of Arterial Highways and Driver Routing Characteristics during a Freeway Detour
}

\author{
Christopher M. Day \\ Purdue University \\ Steven M. Lavrenz \\ Purdue University \\ Howell Li \\ Purdue University \\ Darcy M. Bullock \\ Purdue University
}

SBIR Phase 3 Joint Transportation Research Project

Traffax, Inc.

Purdue University

March 4, 2016

\begin{tabular}{|l|l|}
\hline Deliverable Reference: & D1.8b Case Study \#2 \\
\hline Project Name: & $\begin{array}{l}\text { Sensor Fusion and MOE Development for Off-Line } \\
\text { Traffic Analysis of Real Time Data }\end{array}$ \\
\hline Contractor: & Traffax, Inc. \\
\hline Contract Number: & DTFH61-14-C-00035 \\
\hline Contract Term Start & $9 / 4 / 2014$ \\
\hline Contract Term End & $9 / 4 / 2017$ \\
\hline Key Personnel & Stan Young, Darcy Bullock, Dennis So Ting Fong \\
\hline
\end{tabular}




\section{Recommended Citation}

Day, C. M., S. M. Lavrenz, H. Li, and D. M. Bullock. Traffic Performance of Arterial Highways and Driver Routing Characteristics during a Freeway Detour. Purdue University, West Lafayette, Indiana, 2017. https://doi.org/10.5703/1288284316564

\section{Acknowledgments}

This work was supported by Traffax/USDOT SBIR DTFH6114C00035. The contents of this paper reflect the views of the authors, who are responsible for the facts and the accuracy of the data presented herein, and do not necessarily reflect the official views or policies of the sponsoring organizations. These contents do not constitute a standard, specification, or regulation. 


\begin{abstract}
The temporary closure of a section of northbound I-65 between Indianapolis and Chicago had an enormous impact on the roadways where traffic was detoured. This paper examines the impacts of that closure on arterial highways in rural and suburban settings. Vehicle re-identification travel times are used to investigate route choice decisions and the performance of the detour route, while high-resolution controller data is used to examine the quality of progression for a special signal timing plan designed to handle the detour traffic. The route choice analysis shows that about $60 \%$ of traffic stayed on the official detour, while $40 \%$ used two alternative routes. The three alternative routes had similar median travel times, while one of the two alternatives had much more variability in the travel times. Distributions of travel time and delay per segment were used to examine where delay occurred on the detour route. Most of the delay was attributable to turning movements in rural sections where traffic had to merge into a single lane, while the delay in the signalized portion of the detour route was relatively low. High-resolution data was used to examine the quality of progression in that section in more detail; finding that the signal control policy successfully progressed traffic in the northbound direction along the roadway, and also partially benefited the southbound direction.
\end{abstract}




\section{Introduction}

I-65 is one of the principal highways serving the state of Indiana and connecting the greater Chicago area to Indianapolis and other destinations to the southeast. Approximately 24,000 vehicles per day (including 9,500 trucks) typically use the roadway on a daily basis. In August 2015, one of the bridges in the northbound direction along I-65 began showing signs of movement due to settlement of one of the piers. In response, the Indiana Department of Transportation closed the highway in the northbound direction and commenced repair activities. Ultimately the bridge was reconstructed, which required 31 days.

Figure 1 shows a map of the area affected by the detour, which is the span of I-65 near the cities of Lafayette and Lebanon, Indiana. The northbound lanes were closed between exits 141 and 175. The bridge itself was situated on the section between exits 172 and 175 . However, because of construction activity on the potential alternate route through Lafayette, it was decided not to route the detour through a smaller section in this area. Thus, exits 172 and 168 were both closed. The other options were exits 158 and 141. It was decided to divert traffic at Exit 141 because the ramp at this location directly merges onto US 52, the alternate route, whereas at Exit 158 traffic would have had to make a sharp left turn at the ramp. Thus, northbound traffic on I-65 was closed past mile marker 141.

The official detour carried traffic from I-65 to northbound US 52, which is a four-lane divided highway. Traffic then made a left turn onto Indiana 28, a two-lane rural highway. This route was followed up to a junction with US 231 in Romney, where traffic made a right turn. US 231 is initially a two-lane highway but becomes a four-lane divided highway as it enters the Lafayette / West Lafayette area, where it also becomes a signalized arterial. The detour went through one two-lane signalized left turn along this route. After leaving West Lafayette, the detour route then followed US 231, leaving the divided highway for a two-lane route heading north to rejoin I-65.

Because the detour was taken along routes with many at-grade intersections, a number of alternate routes were possible through the region. However, there are two routes in particular that were likely to attract traffic. For example, instead of making the left turn onto Indiana 28, traffic could potentially stay on US 52 into the Lafayette area, going past the closed bridge and rejoining I-65 at exit 175. This route is highlighted in blue in Figure 1. While this is a shorter distance, the roadway was reduced to one lane in either direction in the Lafayette area because of road construction. Another second route would be to diverge from US 231 in West Lafayette and to follow Indiana 43 up to Exit 178. Except for a four-lane signalized section within West Lafayette, Indiana 43 is for the most part a 2-lane rural highway.

Northbound I-65 was closed for a 24-hour period on Thursday, August 6, to initially inspect the settling bridge. The route was reopened for one day and the bridge continued to settle, leading to the second, 31-day closure beginning on Saturday, August 8. Researchers at Purdue University collaborated with INDOT personnel to begin monitoring traffic on the detour route; initial efforts focused on starting data collection on the rural route using third-party probe vehicle data [1]. About one week later, Bluetooth data collectors were installed along the network and began to 
measure detailed travel characteristics. Figure 1 shows the locations of the ten Bluetooth units that were deployed, labeled "A" through "J".

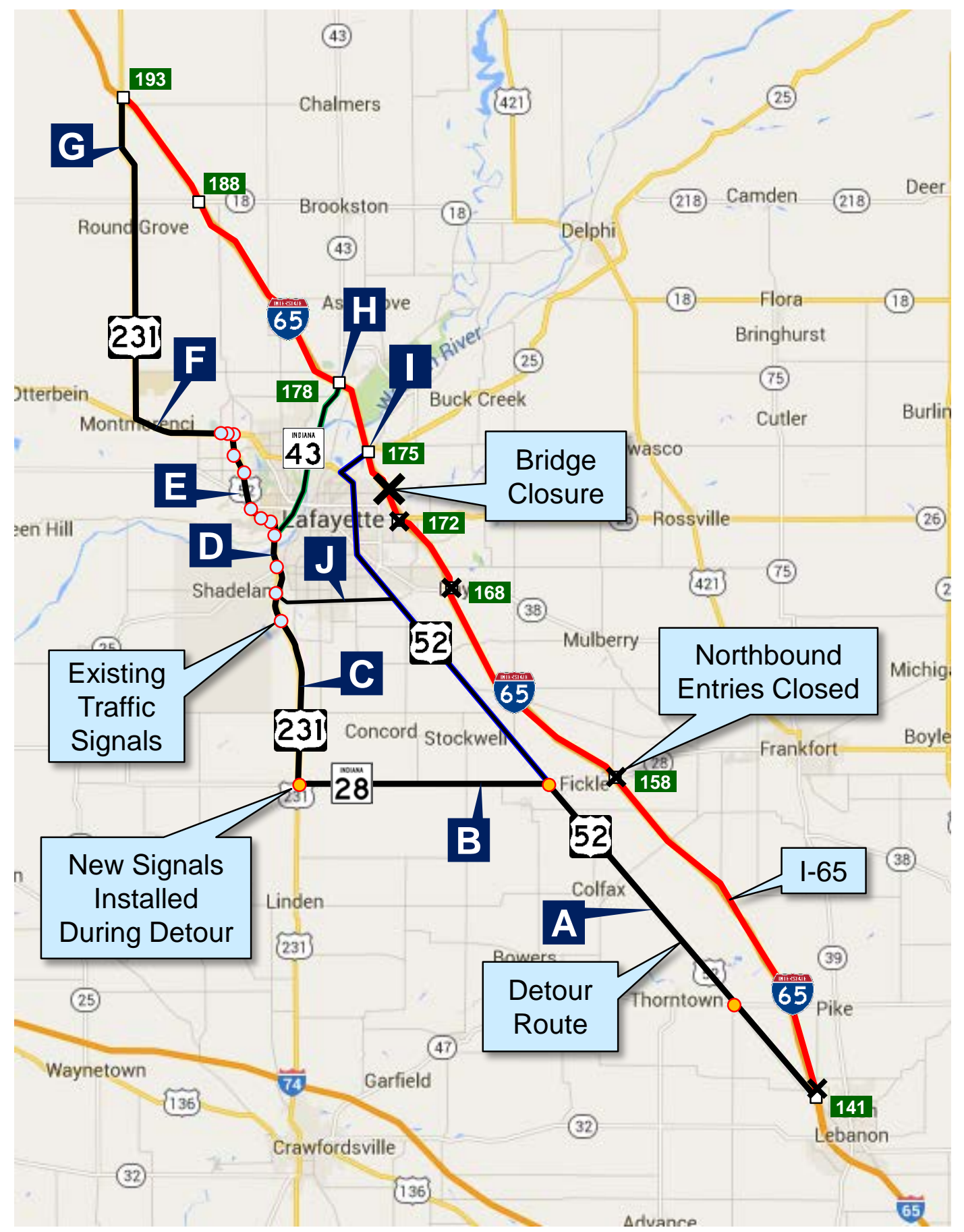

Figure 1. Map of the I-65 detour onto state highways. 
Between the beginning of the closure on August 8, and the deployment of the Bluetooth units on August 14, several actions had been undertaken by INDOT. A series of three new traffic signals were installed at critical locations along US 52 and Indiana 28, and the 12-intersection signalized portion of US 231 in the Lafayette area was coordinated. All of these interventions occurred prior to the deployment of the Bluetooth units. The Bluetooth units remained in the field until they were retrieved on August 23.

The other type of data collection available in the area was high-resolution data from the signal controllers in the signalized portion of US 231. Six intersections had been equipped with data collection capable controllers prior to the I-65 closure. The intersection of US 231 and River Road occurs in the middle of the system and marks the point of departure for Indiana 43 in Figure 1. The northbound volumes from this intersection thus provide a good point of comparison for examining how the volumes changed during the detour.

Figure 2 shows how the northbound volumes fluctuated over a three-week period; the initial closure of I-65 occurred on August 5, a Wednesday. The Interstate was re-opened the following day, but was closed again on Friday, August 7. Correspondingly, the volumes were increased on August 5, decreased again on August 6, and then increased on and after August 7.

Figure 3 provides a weekly comparison of volumes before and after the I-65 detour. The week of July 27, one week prior to the I-65 closure, serves as the "before" data, while volumes from the week of August 17, about two weeks into the detour, is the "after" data. Note that there was a substantial yet brief AM peak in the weekday patterns before the closure. The I-65 closure increased the peak slightly, but also increased volumes for most of the rest of the day, which was a more substantial increase. That is, the northbound direction on US 231 went from having a single peak in the AM, to having traffic volumes similar to that peak throughout the entire day. The weekends also saw a substantial increase, and their volumes during the detour were only marginally lower than the weekdays. 


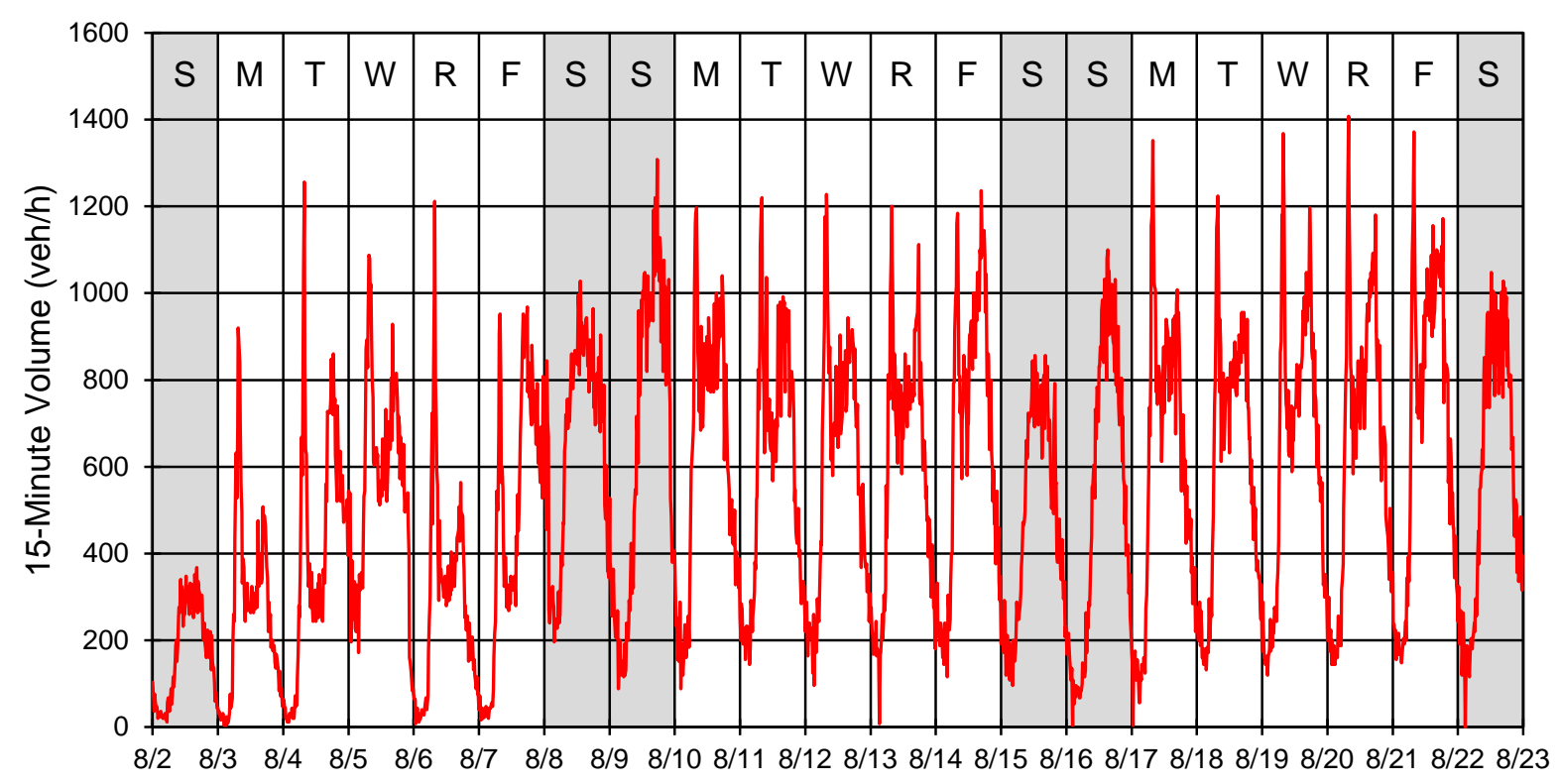

Figure 2. Northbound volumes at US 231 and River Road, 8/2/2015-8/23/2015.

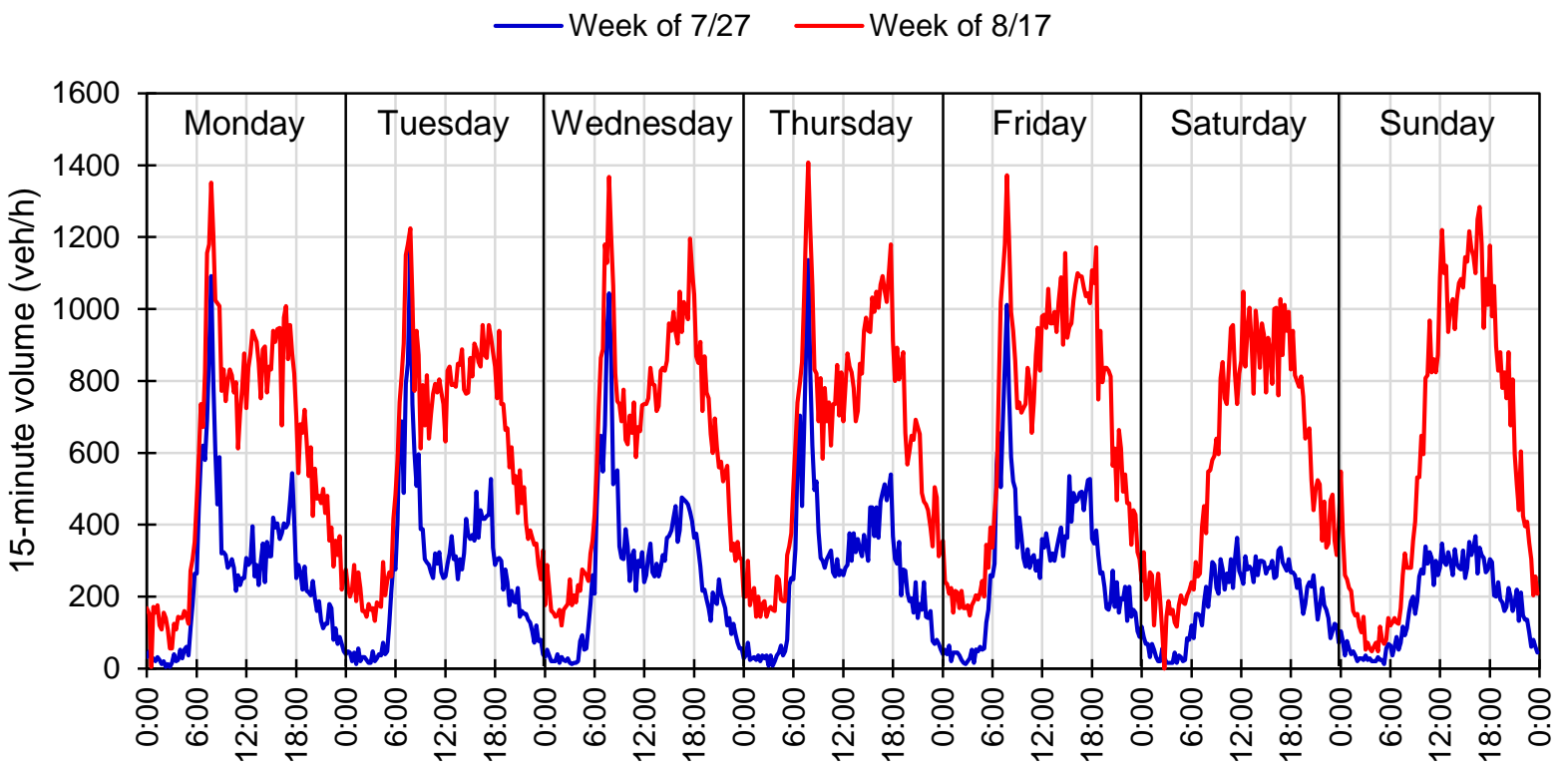

Figure 3. Weekly comparison of traffic volumes before and after the I-65 detour: Northbound at US 231 and River Road. 


\section{Observations from Vehicle Re-Identification}

\section{Matching Characteristics}

Bluetooth MAC address matching [2] was used to sample individual trips from points in the system using the deployed sensors shown in Figure 1. For this study, the travel times between different points were of interest, as well as the origin-destination characteristics [3] revealed by comparing numbers of matches across different points in the system. Before getting into those details, however, it is interesting to briefly review the results of the matching process.

After filtering invalid MAC addresses, the un-matched "raw" data consisted of 431,428 individual MAC records from all of the sensors deployed through the system. Some locations used multiple sensors to reduce the risk of data loss due to equipment failure. Merging data at locations with multiple sensors and "clustering” the raw MAC addresses (which generally appear as several entries within a time window) into unique observable timestamps [4] reduced the number of individual observations to 128,949 entries. These included 29,339 individual MAC addresses. From these, a total of 172,037 point-to-point matches were obtained.

Table 1 shows the number of matches across the ten locations identified in Figure 1. The data covers a span of approximately 9 days. The numbers indicate that locations along the diversion route tended to have the highest number of matches, which is unsurprising since this route had a large volume of traffic all moving in the same direction. There was, therefore, a tendency for vehicles to be matched multiple times among locations A through G. Locations $\mathrm{H}$ and I represent two alternate I-65 re-entry points, and there are a rather large number of matches between locations A and I, showing that this route was rather popular.

Location $\mathrm{J}$ shows another potential alternative route where travelers might have used Veterans Memorial Parkway in Lafayette, rather than Indiana 28, to make the journey from US 52 to US 231. Given that the number of matches between locations A and B is much greater than between A and $\mathrm{J}$ (by a factor of 10), we can conclude that many more travelers stuck to the official detour route than that particular alternative sub-route. Route choice among the alternative I-65 re-entry locations will be examined in more detail later. 
Table 1. Number of raw matches by origin and destination.

\begin{tabular}{|c|c|c|c|c|c|c|c|c|c|c|c|}
\hline & & \multicolumn{10}{|c|}{ Destination } \\
\hline & & A & B & $\mathrm{C}$ & D & $E$ & $F$ & G & $\mathrm{H}$ & I I & $\mathrm{J}$ \\
\hline \multirow{10}{*}{ Origin } & $\mathrm{A}$ & & 8007 & 7474 & 7116 & 5066 & 7026 & 7066 & 761 & 2725 & 785 \\
\hline & $\mathrm{B}$ & 145 & & 7827 & 7391 & 5261 & 6881 & 7015 & 619 & 146 & 49 \\
\hline & C & 149 & 179 & & 10110 & 6450 & 7650 & 7755 & 1072 & 280 & 424 \\
\hline & $\mathrm{D}$ & 213 & 146 & 1221 & & 6756 & 7338 & 7273 & 1064 & 255 & 536 \\
\hline & \begin{tabular}{|l|}
$E$ \\
\end{tabular} & 101 & 54 & 270 & 612 & & 6479 & 6306 & 47 & 133 & 209 \\
\hline & $\mathrm{F}$ & 127 & 96 & 256 & 354 & 409 & & 10094 & 35 & 307 & 125 \\
\hline & $G$ & 74 & 86 & 201 & 199 & 165 & 537 & & 15 & 70 & 22 \\
\hline & $\mathrm{H}$ & 15 & 5 & 185 & 193 & 50 & 37 & 13 & & 115 & 26 \\
\hline & $\mathrm{I}$ & 178 & 63 & 171 & 185 & 94 & 202 & 48 & 94 & & 100 \\
\hline & $\mathrm{J}$ & 387 & 18 & 434 & 834 & 375 & 236 & 141 & 82 & 142 & \\
\hline
\end{tabular}

Figure 4 highlights some interesting characteristics of the matching process in this study. Figure 4a shows the frequency at which matching occurred for all of the individual MAC addresses. For example, callout "i" indicates that there were 5,182 MAC addresses that were matched only one time, while callout "ii" indicates that there was one particular MAC address that was matched 168 times. Note the logarithmic vertical scale. The data exhibits a trend that seems to follow a power law distribution; that is, it is common for a MAC address to be matched once or perhaps several times as it moves along the detour route (which had seven sensors), but increasingly rare for it to be matched dozens or hundreds of times.

Figure 4b shows this trend in a slightly different way. This chart shows the number of times that each individual MAC address was matched, in a Pareto-sorted ranked list, from the most matches to the least matches. For example, callout "i" indicates the vehicle which was matched 168 times, while callout "ii" indicates that 16,765 MAC addresses found matches in total. Recalling that there were 29,339 individual MAC addresses, it would seem that 12,574 MAC addresses were sensed at only one location and had no matches.

The shape of the curve exhibits plateaus at certain numbers of matches corresponding to the "triangular" numbers: $1,3,6,10,15$, and 21 . This is caused by the positioning of seven sensors along the detour route. Because a great deal of traffic tended to follow this route, it was rather common for vehicles to be matched by these numbers of times. For example, a vehicle picked up by two sensors along the route would generate a single match. However, if the vehicle is picked up by three sensors, there would be three matches; and if there were four sensors, there would be six matches among the four sensors. A vehicle recorded by all seven sensors along the route would generate a total of 21 matches. The tendency of traffic to follow the detour route means that it is likely for the same vehicle to be picked up at multiple sensors, thus causing these particular numbers to stand out in Figure 4b. 


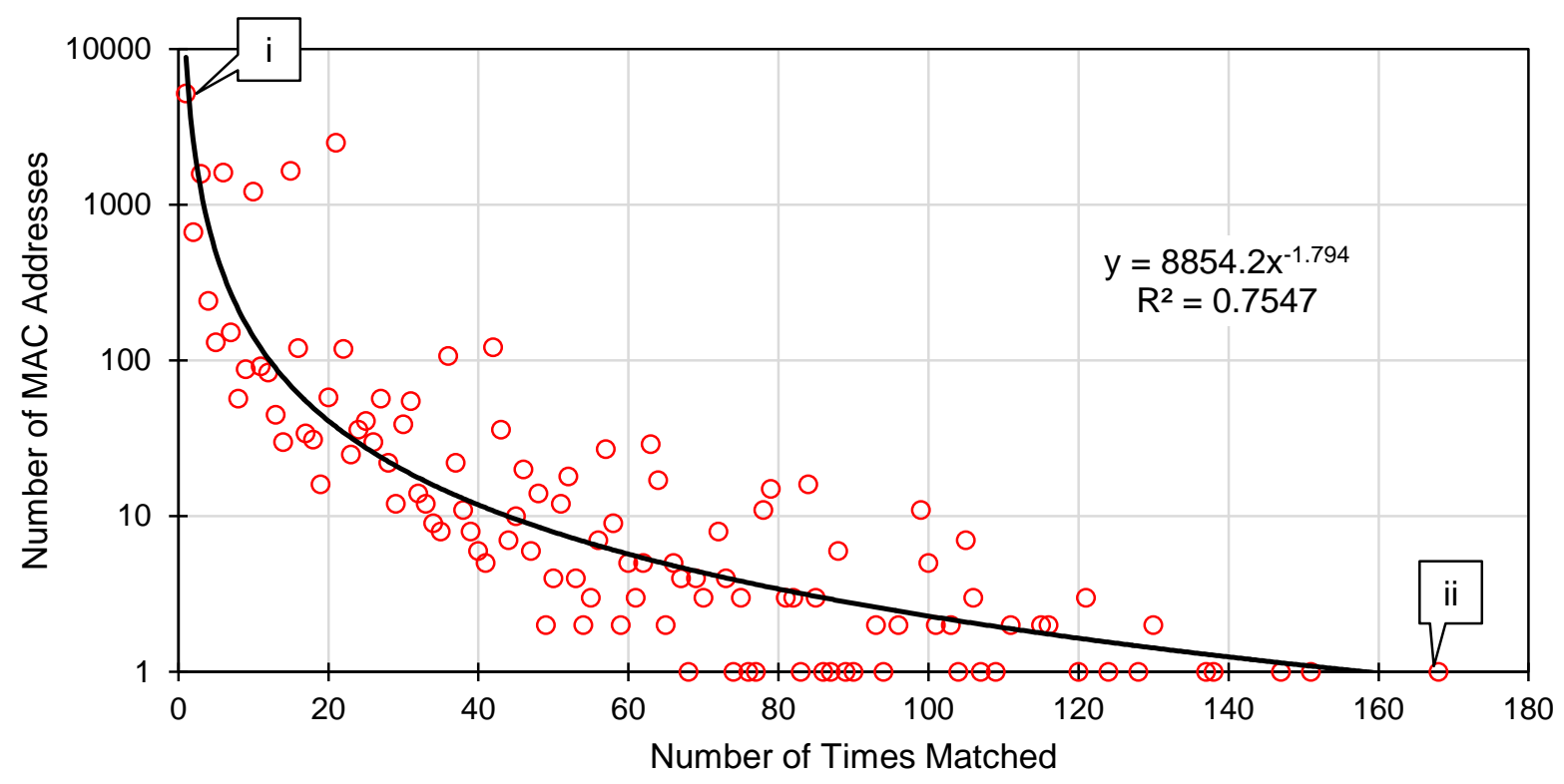

(a) Frequency of the number of times matched.

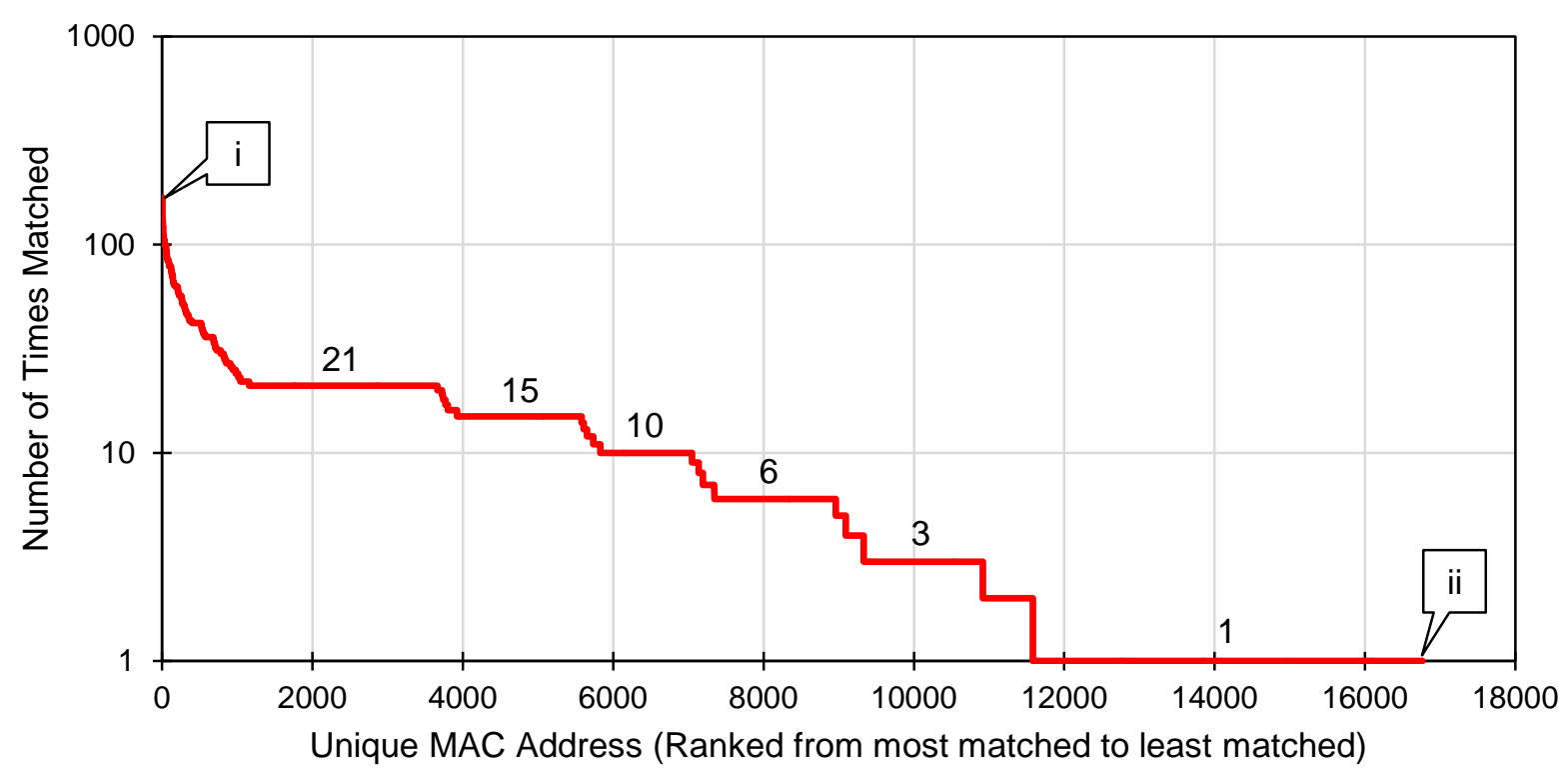

(b) Number of times matched for each individual MAC address.

Figure 4. Bluetooth MAC address matching characteristics. 


\section{Travel Time Data}

Figure 5 shows a plot of the raw travel times along the detour route. Each series of points shows the travel time from location A to different destinations further and further along the detour, up to the final point at location G. Naturally, as distance along the detour increases, so does the travel time. Some "outages” in different matches occur as a result of periods of sensor inactivity. The data also shows the occurrences of secondary incidents on August 18 and August 20. These were both crashes that occurred on the southern end of the detour route [1]. These two incidents greatly increased all the travel times along the route. There is also a daily trend which saw the overall travel time and its variability tending to increase during the midday hours. This is shown by, for example, the slight increase and spreading of the raw data for the "A to F" and "A to G" series during the middle of the day.

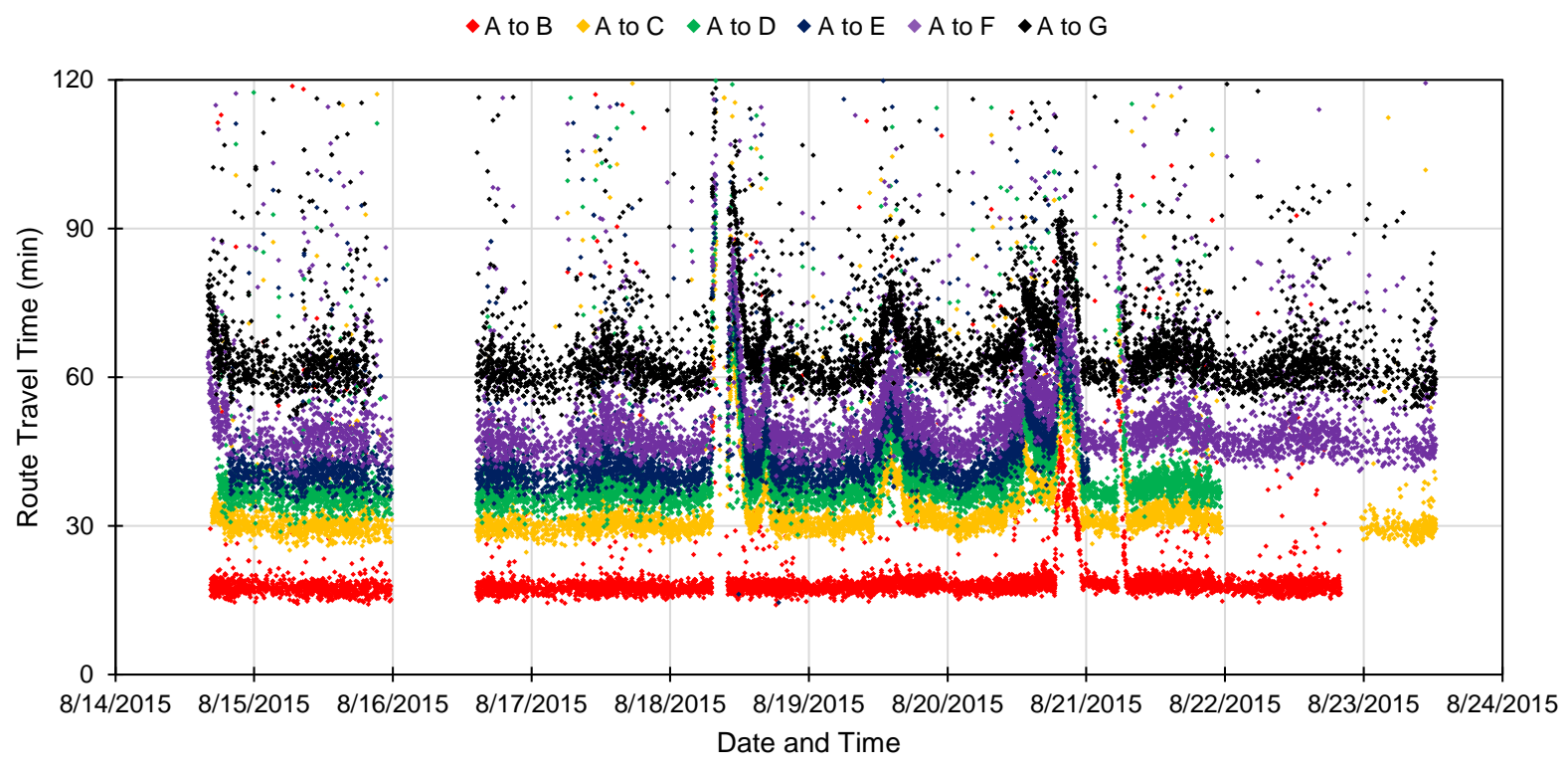

Figure 5. Raw travel times along the detour route. 
Figure 6 shows the raw travel time data from the three alternative routes from location $\mathrm{A}$ at the beginning of the detour to the three I-65 re-entry points: the official route at location G; the Sagamore Parkway route at location I; and the River Rd / Indiana 43 route at location H. The data from the River Rd option disappears after August 19 due to a sensor failure.

The travel times strictly show the distance to re-entry of I-65 and therefore do not reflect the amount of travel time along I-65 after re-entry to reach the same overall distance as other routes which took more time to get back to I-65. The data indicates that there was a tendency for travelers to be able to reach I-65 more quickly by using an alternative route. However, the time savings was questionable at times. For example, on most days, during the middle of the day, it required nearly as much time to use the Sagamore Parkway as it would to remain on the official detour. After considering the travel time on I-65 needed to reach Exit 193 (approximately 15 minutes), it seems doubtful that many travelers using that route would have improved their travel time. The next section will make a better determination of traffic performance on the alternative routes by considering the distributions of the travel time on each.

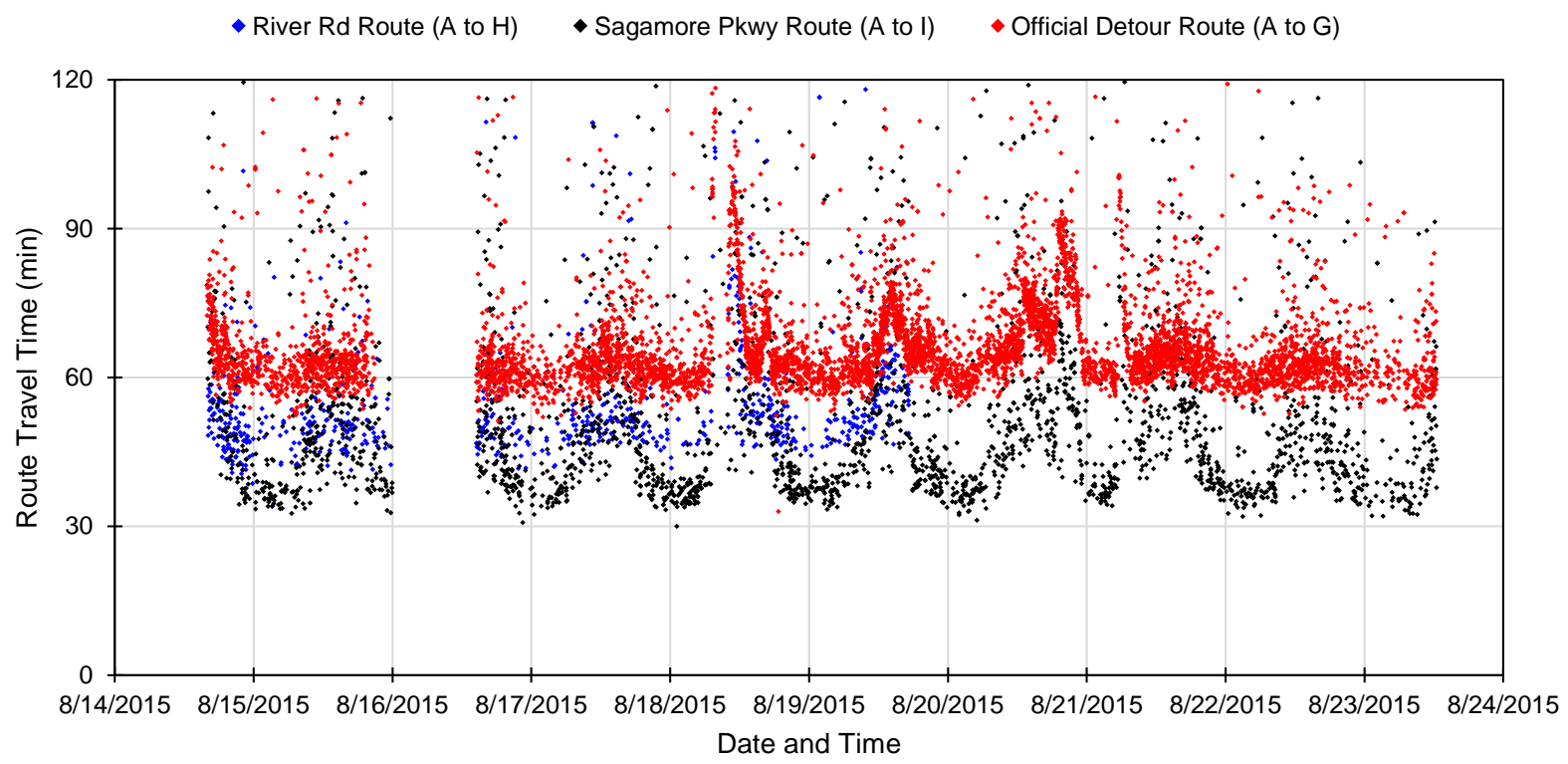

Figure 6. Raw travel times along the three alternative routes. 


\section{Observed Route Choice}

The point clouds of raw travel time measurements in Figure 5 and Figure 6 are useful for viewing the data, but for purposes of analysis it is more helpful to develop a sense of how the travel times are distributed. A simple way to view the distribution of the travel times is with a cumulative frequency diagram (CFD).

Figure 7 shows three CFDs corresponding to the three alternative routes through the detour area. In this case, the travel times on each route were adjusted to account for travel from the endpoint sensor location to the same location on I-65, at exit 193. It was presumed for this purpose that travel along the remaining portion of the route occurred at the free flow speed. The median $\left(50^{\text {th }}\right.$ percentile) travel time among the three routes was quite similar, falling within a 5-minute range. The overall shape of the distribution was very similar for the official detour route and the River Road route, while the Sagamore Parkway route was substantially more spread out, indicating that there was much more variability in the travel time along that route.

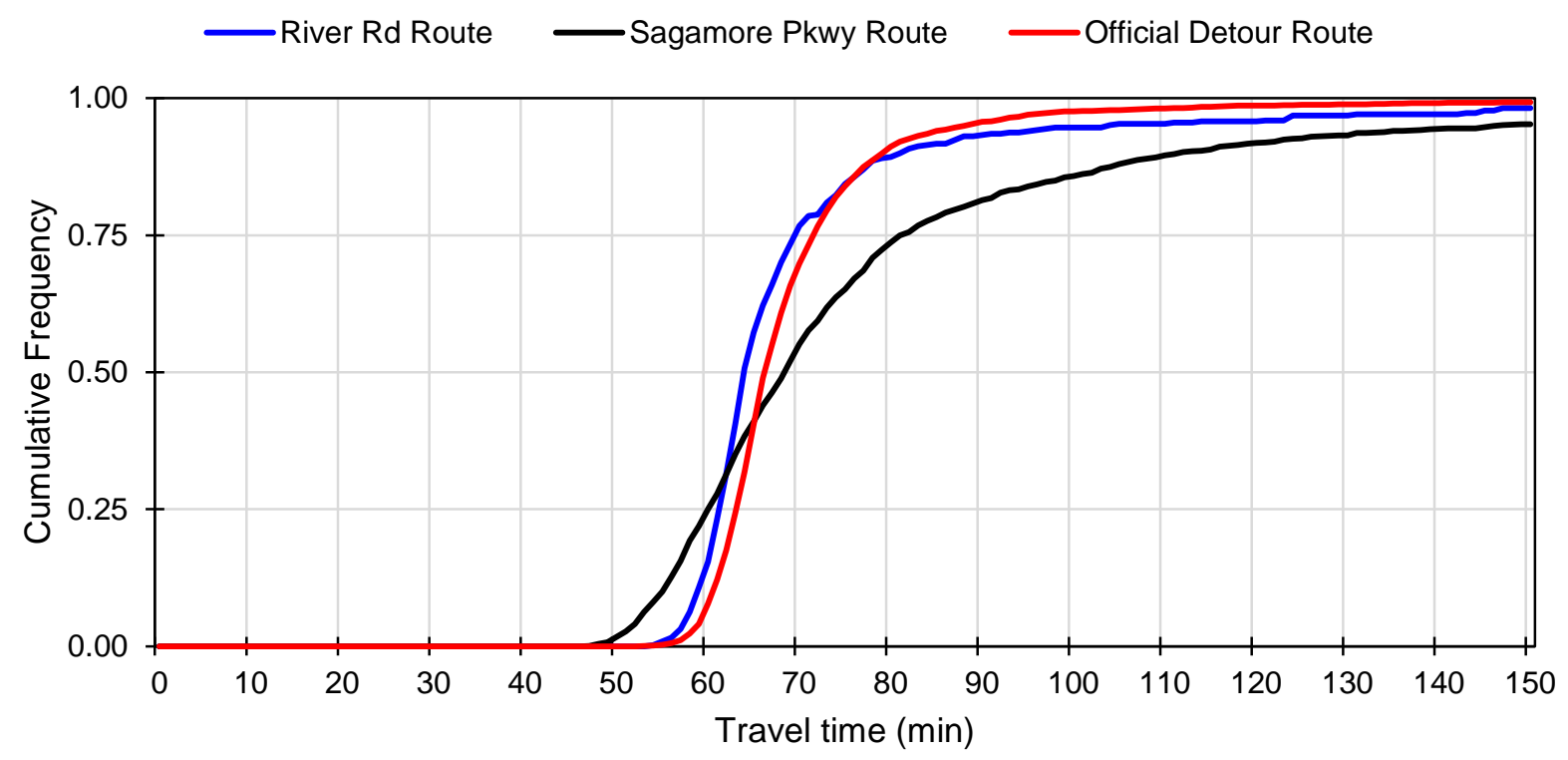

Figure 7. Travel times by route (adjusted for travel along I-65 to reach Exit 193). 
To quantify route choice, the proportional numbers of matches between the endpoint sensor pairs of the three alternative routes were tabulated. Data from August 14 through August 19 were used for this purpose as this reflected the time period where data was available for all three routes, as shown by Figure 6 . The resulting values, along with some statistical properties of the travel time distributions, are shown in Figure 8. The median value is shown, as well as the interquartile range (IQR), which is the difference between the $75^{\text {th }}$ and $25^{\text {th }}$ percentiles. The IQR is a measure of the variability in the travel times.

Figure 8 shows that the majority of travelers used the detour route. Their median travel time, 67 minutes, is 23 minutes longer than their travel time had they been able to continue northbound on I-65 (44 minutes from mile 141 to mile 193). About 1 in 4 travelers opted to remain on Sagamore Parkway and follow it to re-enter I-65 at mile 175. Their travel times ended up being a few minutes longer, but the variability is much greater. Whereas the typical travel times on the official detour ranged within 8 minutes, there was a spread of about 21 minutes on the Sagamore Parkway route. This is not unexpected, considering that there was a substantial amount of road work going on along that route during the I-65 detour. Finally, the River Road route ended up having a slightly lower travel time than the official detour route, but this was the least popular route.

The rather close similarity of the median travel times among the three routes suggests that user equilibrium was established, at least approximately, by the route choice decisions of travelers during the I-65 detour. One might further debate whether travelers were more interested in reducing their overall travel time from endpoint to endpoint, or their travel time to return to I-65. Travel times on the shortest distance route to re-enter I-65 were slightly longer than the other routes, and those travel times had the most variability, yet this route attracted a substantial portion of the overall traffic. 


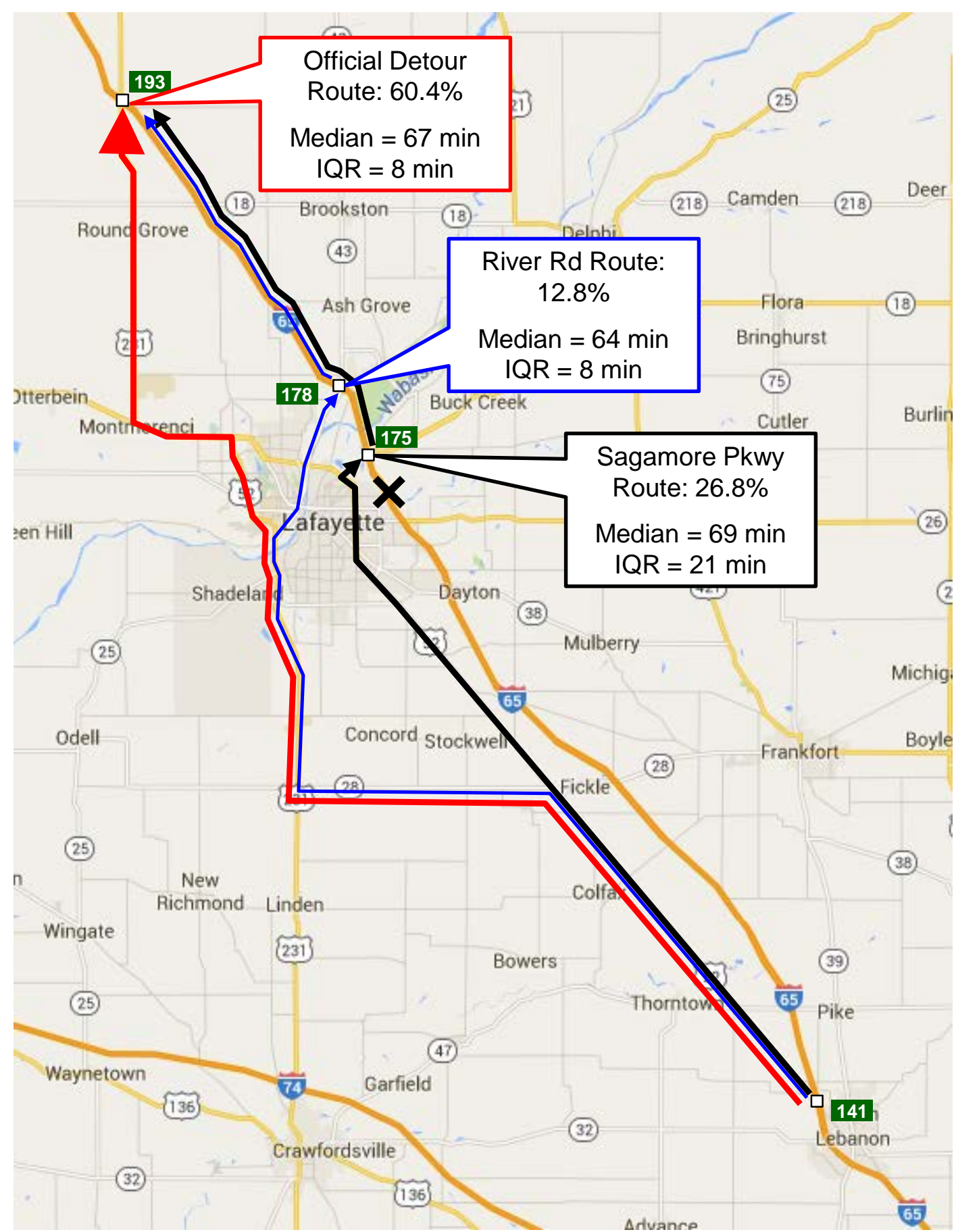

Figure 8. Map of O-D routes taken and travel times experienced on each. 


\section{Traffic Performance along the Detour Route}

\section{Travel Times and Segment Delays}

Seven sensor locations were used along the detour route, defining six potential segments along the route for measuring travel times, as well as several options for viewing the marginal increases in travel times as travelers move along the route. Two ways of visualizing travel time to quantify the cumulative effects along a route are origin-based and destination-based travel time distributions [5]. These respectively use a common reference point at the start and end of the route to visualize the cumulative effects of the route choice on the travel times.

Figure 9 shows a series of travel time CFDs from the origin perspective (Figure 9a) and the destination perspective (Figure 9b). Both plots show increasing travel times among the series shown as the distance increases. In addition, both plots also show that the distributions are increasing their slopes as the distance accumulates, meaning that the travel time becomes more variable (less reliable) as the distance increases. This is as expected; the longer the route, the more opportunities for slowing and stopping at intersections. An increase of the slope from one line to the next indicates a substantial increase in variability. In the origin-based travel time plot (Figure 9a), the slopes of the lines are generally similar from "A to C" and to the right, which suggests an increase in variability between $\mathrm{B}$ and $\mathrm{C}$. In the destination-based travel time plot (Figure 9b), the slopes of the lines are about the same moving from left to right, except for the "B to G" and "A to G" lines which are progressively less steep. This suggests that variability increases substantially in the last two segments. 


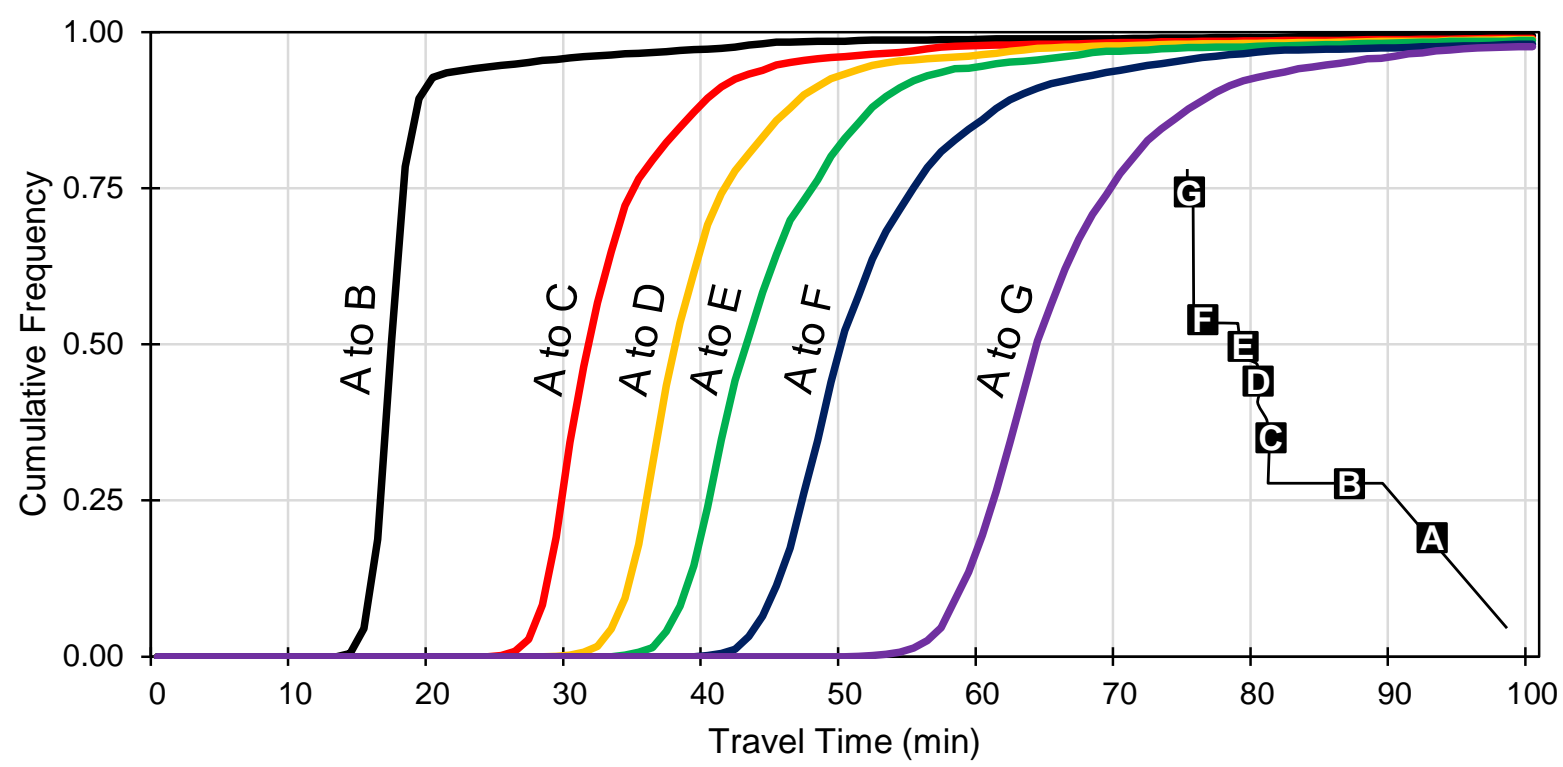

(a) Origin-based travel time (from entry to various subsequent points).

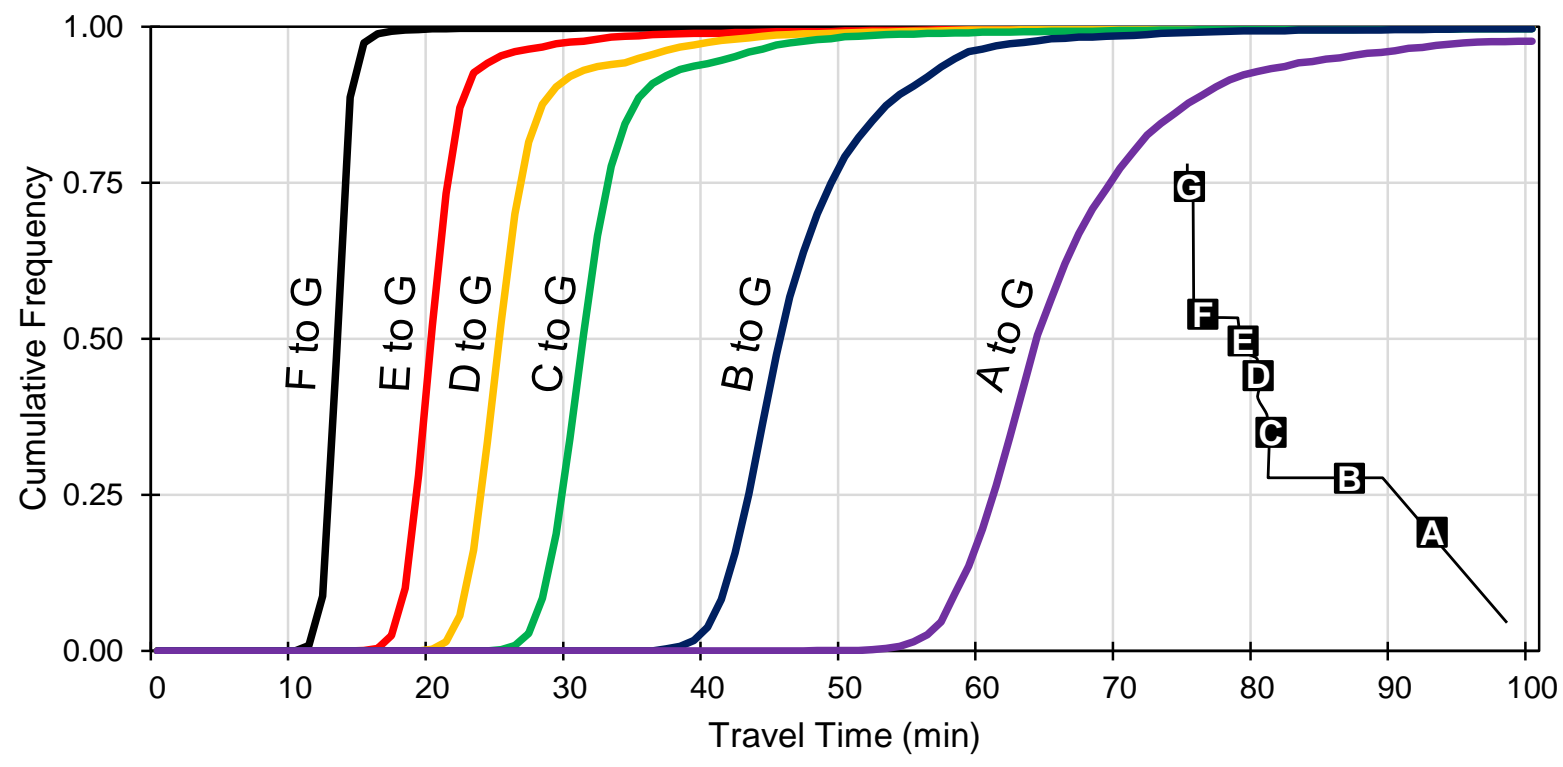

(b) Destination-based travel time (from various preceding points to exit).

Figure 9. Travel times along the detour route. 
The differences between segments are shown a little more clearly by considering the delays incurred on each segment. These are calculated by measuring the travel times between neighboring sensors on each segment, and subtracting the free flow travel time from these. Figure 10 shows CFDs of delay by segment for both the northbound direction of travel (Figure 10a) and the southbound (Figure 10b) along the detour route. The southbound CFDs are less smooth because the amount of traffic going in the opposite direction was far less. However, there were still enough matches to be able to create southbound CFDs for every segment on the detour route.

The results show that delay is relatively low for the northbound segments $\mathrm{C}$ to $\mathrm{D}, \mathrm{D}$ to $\mathrm{E}$, and $\mathrm{F}$ to $G$ (Figure 10a). The corresponding southbound segments, D to C, E to D, and G to F, also have relatively low amounts of delay (Figure 10b). These segments include the signalized portion of US 231. Despite there being numerous traffic signals on segments C to D and D to E, the median delay remained less than one minute. Northbound segment $\mathrm{E}$ to $\mathrm{F}$ has somewhat higher delay, which may result from the influence of a signalized turn on the route (Figure 10a). However, the corresponding southbound segment $\mathrm{F}$ to $\mathrm{E}$ does not have a higher amount of delay (Figure 10b).

The first two segments of the northbound detour, A to B and B to C, both have substantially higher delay than the other segments (Figure 10a). A to B in particular has a median delay of about 6.5 minutes. This is likely due to the fact that the detour traffic must merge into one lane and execute a left turn, when turning from US 52 to Indiana 28. Interestingly, a substantial albeit slightly lower amount of delay is also incurred in the opposing direction, B to A (Figure 10b). The reason for this is not clear, although it may be due to operations at the intersection of US 52 and Indiana 28. The next segment, B to C, also has somewhat high delay as well as substantial variability (Figure 10a). This segment includes a right turn from Indiana 25 to US 231. The opposing segment, $\mathrm{C}$ to $\mathrm{B}$, also has somewhat higher delay (Figure 10b), perhaps because of the corresponding left turn movement from US 231 to Indiana 25. 


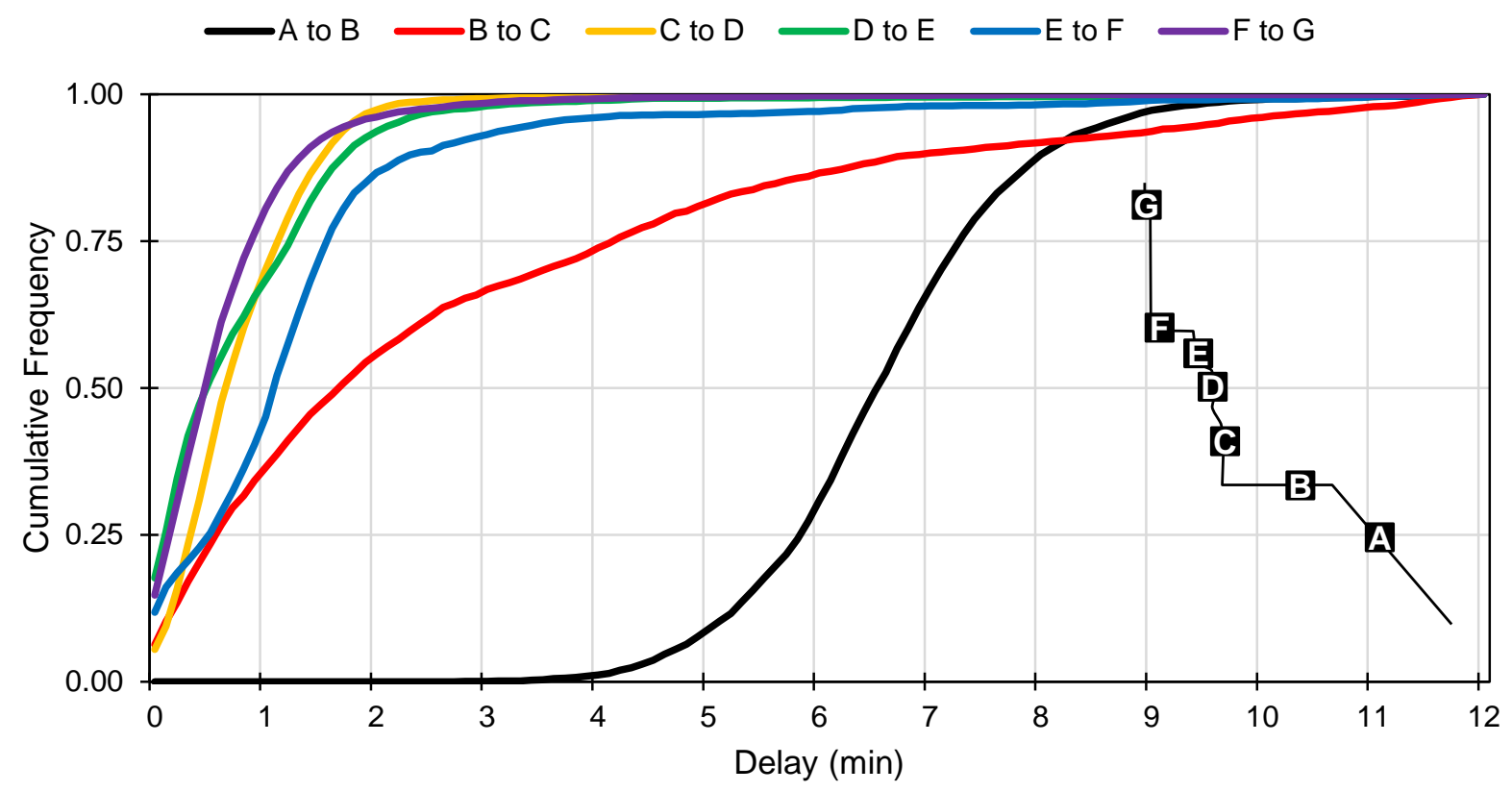

(a) Northbound.

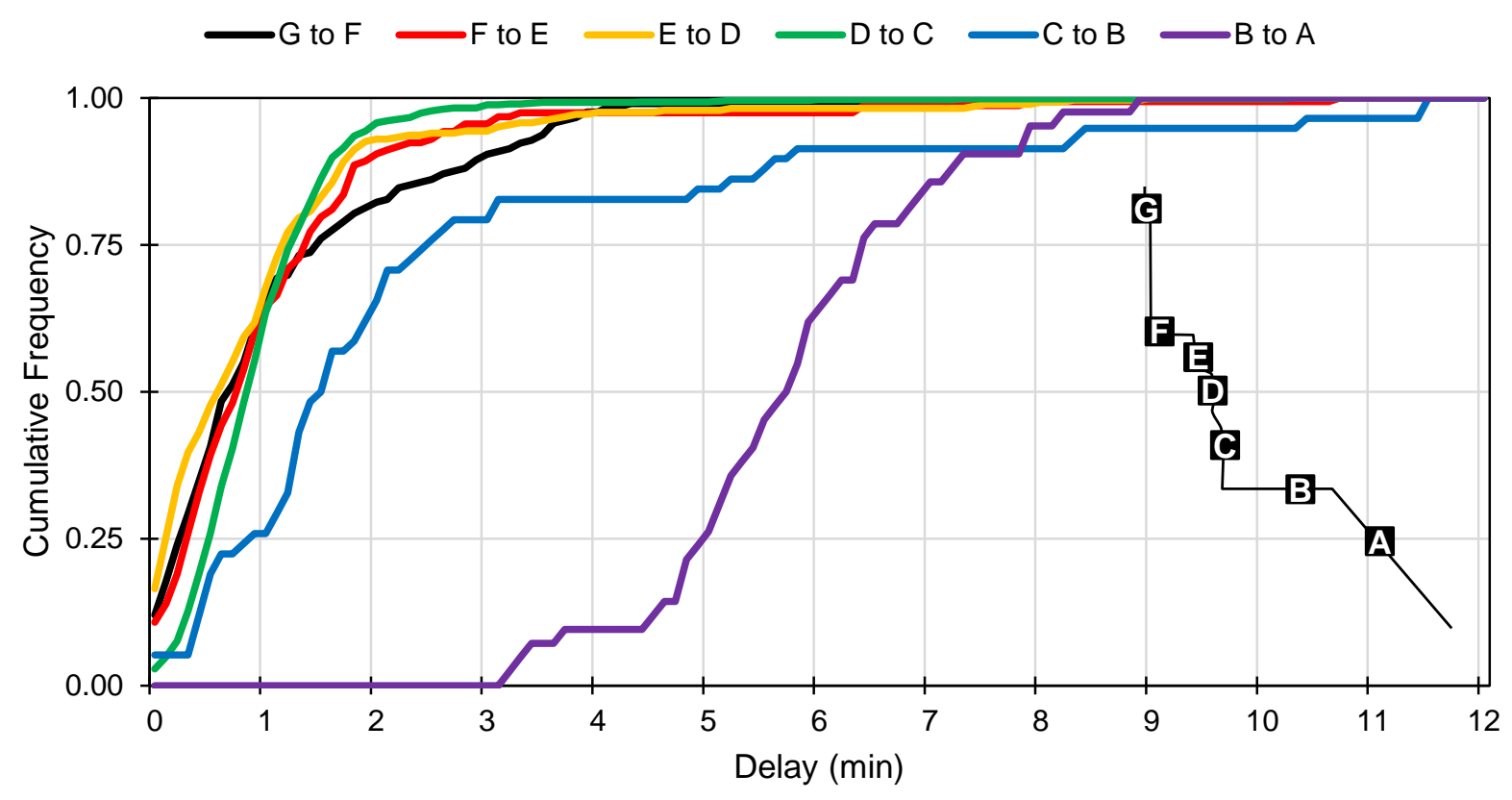

(b) Southbound.

Figure 10. Delay by segment in both directions. 


\section{Qualitative Evaluation of US 231 Signal Timing}

In response to the dramatically changed traffic patterns during the I-65 closure, INDOT engineers implemented a special signal timing plan intended to handle the increase in northbound traffic on US 231. The goal of the engineers was to achieve excellent progression in the northbound direction, with as many vehicles arriving on green as possible for movement in that direction. The delay distributions in Figure 10 suggest that these goals were achieved in general, as the median delays for the segments going through the signalized portion of US 231 are generally less than one minute, with the exception of segment $\mathrm{E}$ to $\mathrm{F}$.

Figure 11 shows a map of the signalized portion of US 231. There are 12 signalized intersections in total in this section. Intersection 9 (Cumberland Avenue) was still under construction at the beginning of the detour, and the traffic signals at this location were not operational until August 20. At the beginning of the I-65 closure, six of the intersections had ongoing high-resolution data collection (4, 5, 6, 7, 8, and 10). This capability was also added to intersections 1 and 2 early in the days of the I-65 closure, but the rest of the system had not been similarly equipped at the time when the Bluetooth monitoring equipment was deployed. Therefore, high-resolution data is only available for eight of the ten intersections along the north-south portion of US 231, and not from the two intersections along the east-west portion (11 and 12).

Nevertheless, it is still possible from the data that is available to make some determinations as to whether the timing plan achieved its goals, at least for the majority of the intersections. One way of visualizing the quality of progression is to use a graphical tool called the Purdue Coordination Diagram [6]. This chart shows the vehicle arrival times, as measured by a setback detector along the arterial, relative to the duration of green.

Figure 12 and Figure 13 show representative PCDs from US 231 during the detour, while the system was running the special timing plan. Each individual chart within the two figures shows a 24-hour span of data for one particular signalized approach, as labeled. The vertical position of each dot shows the arrival time during cycle of an individual vehicle, while the horizontal position shows the time of day in which it occurred. Overlaid on top of this are green and red traces that show the beginning and end of green during each cycle; the region between these, shaded green, shows the time in cycle in which the signal was green. In summary, it is desirable to have as many dots as possible within the shaded green region, which is indicative of good progression. An abundance of dots in the non-shaded region below the green line indicates poor progression. 


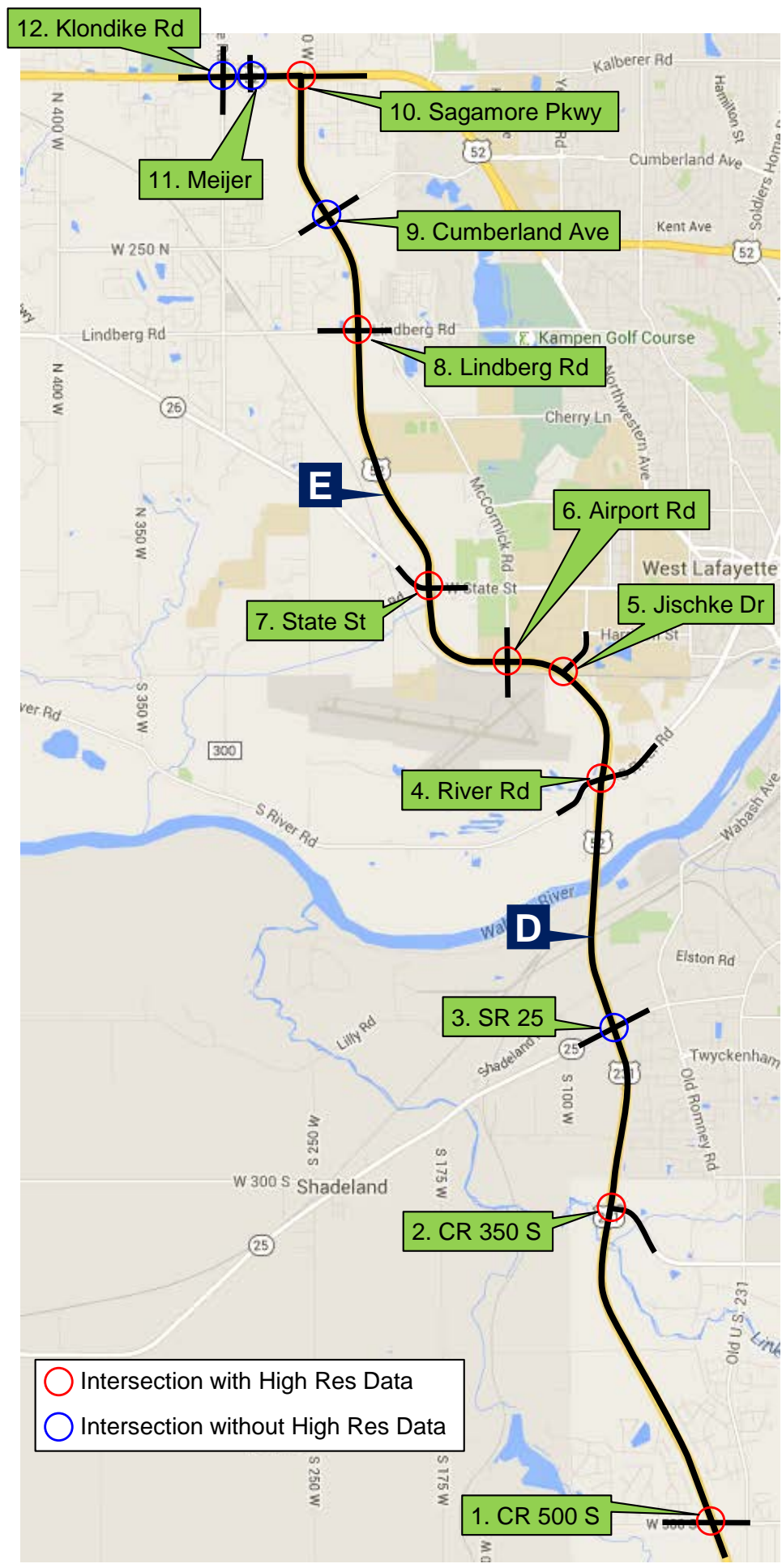

Figure 11. Map of the signalized portion of US 231. 
A visual survey of the PCDs in Figure 12 and Figure 13 reveals that the engineers used a policy that favored long green times along the arterial. For example, the cycle length (indicated by the upper red line) is 150 seconds, and nearly all of the signalized approaches turn green well before 60 seconds into the cycle. This means that the detour timing plan strongly favors the arterial in terms of the distribution of green times. This strategy increases the likelihood of capturing more vehicle arrivals in green, and is probably why there was relatively low delay in both directions along the arterial, as Figure 10 shows.

Progression in the northbound direction has a nearly ideal appearance, with all of the northbound PCDs exhibiting large clusters of vehicles coincident with the green. The only exceptions are the northbound approach at Int. 4, which has a substantial amount of arrivals in red during the AM and PM peaks, likely due to local traffic turning in from other movements at the upstream intersection; and Int. 1, which has random arrivals. Most of the approaches in the southbound direction also have the same pattern, although the numbers of vehicles are far less than in the northbound direction. Southbound at Int. 8 and Int. 1 seem to show a fair number of arrivals in red.

While it is informative to view the details of traffic behavior with the PCDs, these qualitative observations can also be summarized with quantitative performance measures, which allow the performance to be related more succinctly. Three performance measures are of interest in this case:

- The percent on green (POG) simply gives the proportion of the arriving traffic that was coincident with green. This number is indicative of the overall quality of progression, but it tends to be inflated with long cycle lengths and long green times. For example, if the signal was green for $100 \%$ of the time, POG would also naturally become $100 \%$, and vice versa.

- The green-to-cycle ratio, $g / C$, is another metric that expresses the amount of cycle time being used to serve the approach. This is helpful for understanding the degree to which the signal policy favors the mainline movements.

- The platoon ratio, $R_{p}$, is equal to the POG divided by the $g / C$ ratio. This metric provides an alternative measure of the quality of progression that takes into account whether longer cycle lengths and green times are being used. A value of $R_{p}=1.0$ is typical of purely random arrivals, where POG and $g / C$ are equal. Values of $R_{p}<1.0$ indicate that progression is relatively poor, while values of $R_{p}>1.0$ indicate relatively good progression. More specifically, progression is considered relatively poor when the POG is less than the $g / C$ ratio. This means that the arrivals are not scheduled efficiently. Conversely, when POG is higher than the $g / C$ ratio, this indicates that the platoons are well aligned with the green. 

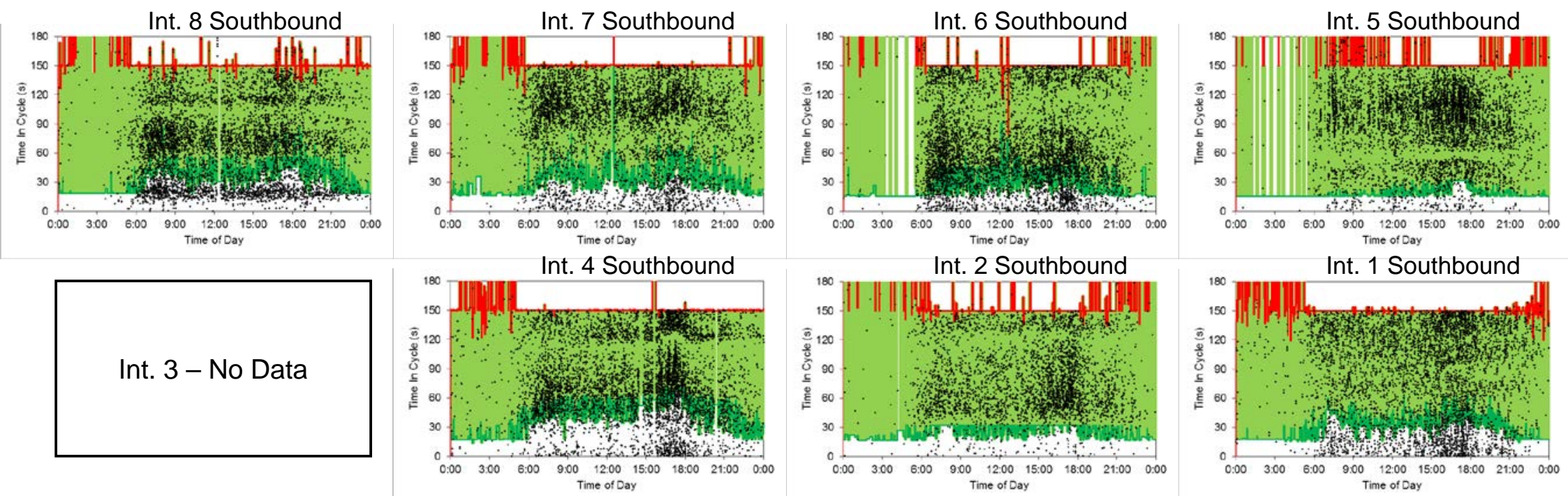

Figure 12. Southbound PCDs from the US 231 corridor during the diversion route. 

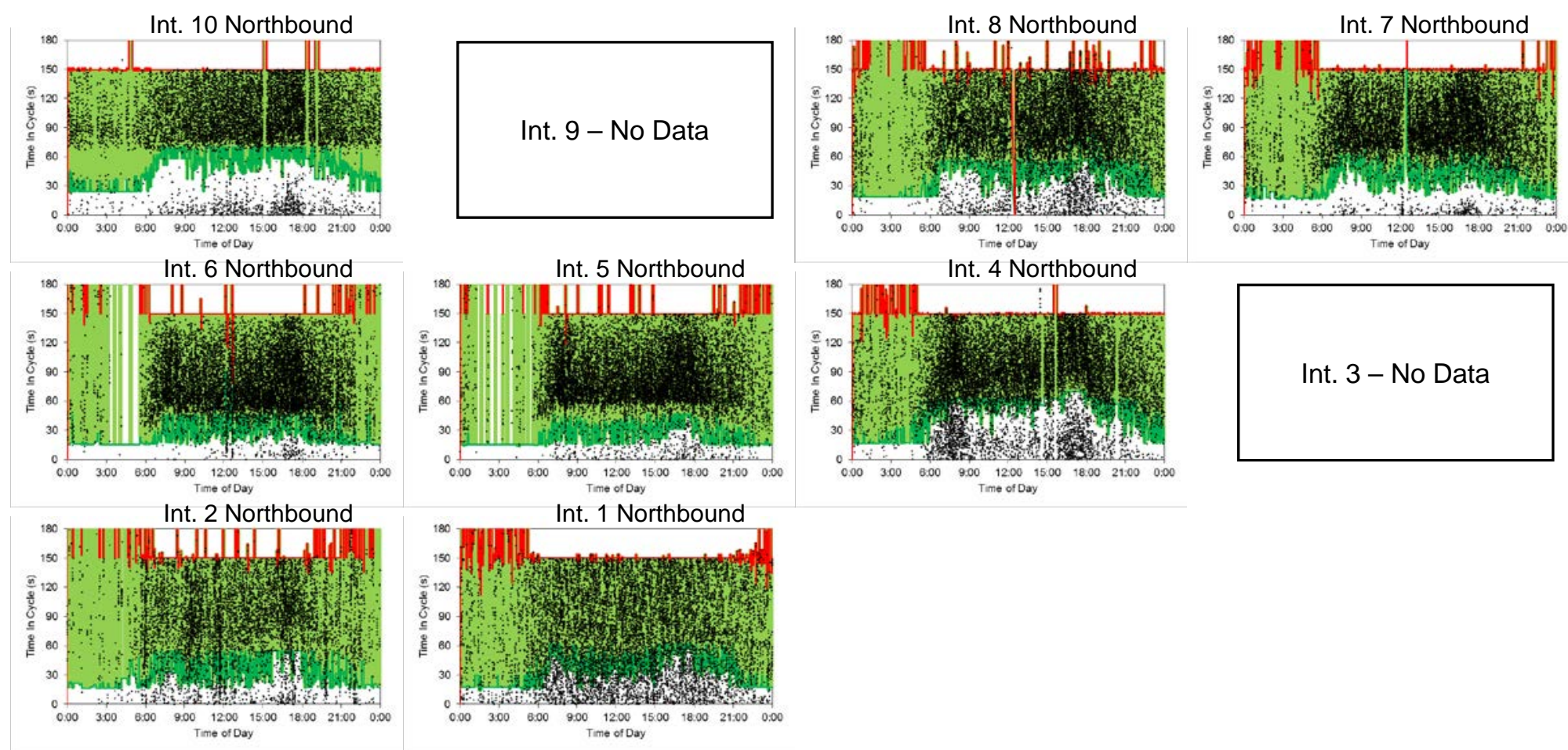

Figure 13. Northbound PCDs from the US 231 corridor during the diversion route. 
Table 2 shows the quantitative performance measures that correspond to the PCDs in Figure 12. Clearly, in terms of POG, all of the approaches had rather high values. All of them are above $70 \%$, and many of them are above $90 \%$. In the northbound direction, for example, POG values are above $80 \%$ for all the approaches except for the entry, where random arrivals prevailed. Of these, POG values around 95\% are sustained through Intersections 5, 6, and 7. The southbound direction has less exceptional progression, yet the POG values remain relatively high.

The $g / C$ ratios, meanwhile, show that the timing plan strongly favors the mainline. With the exception of northbound at Intersections 4 and 10 , all of the $g / C$ ratios are above $75 \%$. The platoon ratio $\left(R_{p}\right)$ values take these into consideration. These show that northbound progression tends to be fairly good for all of the approaches; the value is greater than 1 . The quality of progression is perhaps the best on the northbound approach to Int. 10, because a very high POG is achieved by a relatively small $g / C$ ratio. In the southbound direction, however, there are several approaches where $R_{p}$ is actually less than 1 , because POG is less than $g / C$. This indicates locations where there are substantial arrivals in red. Even though high POG is still achieved on these approaches, the fact that the $g / C$ ratio is higher means that if traffic were completely random, more vehicles would arrive on green. But because traffic is not random, inefficient offsets are causing platoons to arrive during red, which is why POG is less than $g / C$ for some approaches. Apart from these, the overall performance in the southbound direction indicates successful progression by virtue of long green times.

However, given that the main objective of the engineers in devising the timing plan was to progress as much traffic as possible in the direction of the detour, the results show that this was achieved. The POG values are exceptional, and $R_{p}$ values exceed 1.0 in the northbound direction for all approaches except the entry. This means that platoons were successfully created and progressed through the system in the northbound direction. The opposing direction happened to benefit from the fact that long green times were used to create a large northbound green band. In general, southbound progression fared rather well as a result. 
Table 2. Summary performance measures for progression along US 231.

\begin{tabular}{|l|l|r|r|r|r|r|}
\hline & \multicolumn{2}{|l|}{ Southbound } & \multicolumn{2}{l|}{ Northbound } & \multicolumn{2}{l|}{} \\
\hline Intersection & POG & \multicolumn{1}{l|}{$g / C$} & $R_{p}$ & POG & $g / C$ & $R_{p}$ \\
\hline 10 & N/A & & $90.2 \%$ & $66.8 \%$ & 1.35 \\
\hline 9 & No Data & & No Data \\
\hline 8 & $70.3 \%$ & $77.4 \%$ & 0.91 & $88.2 \%$ & $76.3 \%$ & 1.15 \\
\hline 7 & $82.8 \%$ & $79.7 \%$ & 1.04 & $94.5 \%$ & $77.6 \%$ & 1.22 \\
\hline 6 & $79.7 \%$ & $85.9 \%$ & 0.93 & $95.8 \%$ & $86.1 \%$ & 1.11 \\
\hline 5 & $96.4 \%$ & $91.7 \%$ & 1.05 & $96.4 \%$ & $86.4 \%$ & 1.12 \\
\hline 4 & $74.5 \%$ & $72.1 \%$ & 1.03 & $80.8 \%$ & $68.4 \%$ & 1.18 \\
\hline 3 & $95.8 \%$ & $87.0 \%$ & 1.10 & $89.5 \%$ & $82.4 \%$ & 1.09 \\
\hline 2 & $75.6 \%$ & $80.5 \%$ & 0.94 & $76.0 \%$ & $77.4 \%$ & 0.98 \\
\hline 1
\end{tabular}

\section{Conclusions}

This paper explored characteristics of traffic performance on arterial highways in rural and suburban settings, when those highways were subjected to an enormous influx of traffic because of a bridge closure on a parallel Interstate highway. Vehicle re-identification travel time data, consisting of Bluetooth MAC address matches, and high-resolution signal controller data were used to develop qualitative and quantitative insights into the performance of the system under these conditions. Although the travel time data was only available for a 1-week period of the month-long detour period, this was sufficient to provide insights on route choice and the location of delay in the system.

Route choice characteristics were presented for three alternative routes through the region affected by the detour, leading to three alternative re-entry points to the Interstate after the bridge closure. The median travel times from the three routes ended up being very similar, although one route had far less reliability (greater variability) than the others. The official detour retained the majority of travelers, while about $40 \%$ used the two alternative routes.

Travel time and delay distributions were also explored on the detour route, which identified the sections of roadway where most of the delay was incurred. It was found that delay was associated with a few significant turning movements on rural sections of the detour route, where traffic was restricted to a single lane. Interestingly, there was relatively little delay associated with the signalized portion of the route. A closer inspection of the quality of progression using high resolution data revealed why this was the case. The use of a long cycle length and long green times along the arterial had the effect of producing nearly ideal progression in the direction of the detour. The long green times also tended to benefit the opposing direction as well. The number of vehicles arriving on green was very high in both directions, corresponding to relatively low amounts of delay seen in the signalized sections of the detour. 


\section{Acknowledgments}

This work was supported in part by USDOT SBIR project (contract number DTFH61-14-C00035) through Traffax, Inc. and Purdue University. The contents of this paper reflect the views of the authors, who are responsible for the facts and the accuracy of the data presented herein, and do not necessarily reflect the official views or policies of the sponsoring organizations. These contents do not constitute a standard, specification, or regulation.

\section{References}

1. McNamara, M., H. Li, S. Remias, L. Richardson, E. Cox, D. Horton, and D.M. Bullock. Using real-time probe vehicle data to manage unplanned detour routes. ITE Journal, December 2015, 32-37.

2. Wasson, J.S., J.R. Sturdevant, and D.M. Bullock. "Real-time travel time estimates using media access control address matching.” ITE Journal, Vol. 78, 20-23, 2008.

3. Hainen, A.M., J.S. Wasson, S.M.L. Hubbard, S.M. Remias, G.D. Farnsworth, and D.M. Bullock. "Estimating route choice and travel time reliability with field observations of Bluetooth probe vehicles.” Transportation Research Record No. 2256, 43-50, 2011.

4. Day, C.M., J.S. Wasson, T.M. Brennan, and D.M. Bullock. Application of Travel Time and Travel Time Reliability Information for Traffic Management, Media/Public Outreach During Construction, and Innovative Contracting. Publication FHWA/IN/JTRP-2012/06. Joint Transportation Research Program, Indiana Department of Transportation and Purdue University, West Lafayette, Indiana, 2012.

5. Remias, S.M., A.M. Hainen, C.M. Day, T.M. Brennan, H. Li, E.M. Rivera-Hernandez, J.R. Sturdevant, S.E. Young, and D.M. Bullock. Performance characterization of arterial traffic flow with probe vehicle data. Transportation Research Record No. 2380, 10-21, 2013.

6. Day, C.M., R. Haseman, H. Premachandra, T.M. Brennan, J.S. Wasson, J.R. Sturdevant, and D.M. Bullock. Evaluation of arterial signal coordination: methodologies for visualizing high-resolution event data and measuring travel time.

Transportation Research Record No. 2192, 37-49, 2010. 


\section{Report Sponsor}

The "Small Business Innovation Development Act of 1982" (Pub. L. No. 97-219), along with reauthorizing legislation (Pub. L. No. 99-443 and Pub. L. No. 102-564, the "Small Business Research and Development Enhancement Act of 1992"), seeks to encourage the initiative of the private sector and to use small business effectively to meet federal research and development objectives. To comply with statutory obligations of the Act, the U.S. Department of Transportation established the Small Business Innovation Research (SBIR) Program, which conforms to the guidelines and regulations provided by the Small Business Administration. Annually, small businesses are solicited to submit innovative research proposals that address the high-priority requirements of the U.S. Department of Transportation and that have potential for commercialization.

This report was developed through a partnership between Traffax, Inc., and Purdue University with funding from a Phase III SBIR contract (DTFH6114C00035) with the Federal Highway Administration. The project, entitled "Sensor Fusion and MOE Development for Off-Line Traffic Analysis of Real Time Data," created and refined methods and tools for the characterization of performance along arterial corridors.

\section{Publication}

This report is part of a series of reports published in collaboration with USDOT, Traffax, Inc., and Purdue University. The full report series is available for download at http://docs.lib.purdue .edu/apmtp/.

\section{Open Access and Collaboration with Purdue University}

The Indiana legislature established the Joint Highway Research Project in 1937. In 1997, this collaborative venture between the Indiana Department of Transportation and Purdue University was renamed as the Joint Transportation Research Program (JTRP) to reflect state and national efforts to integrate the management and operation of various transportation modes. Since 1937, the JTRP program has published over 1,600 technical reports. In 2010, the JTRP partnered with the Purdue University Libraries to incorporate these technical reports in the University's open access digital repository and to develop production processes for rapidly disseminating new research reports via this repository. Affiliated publications have also recently been added to the collection. As of 2017, the JTRP collection had over 1.5 million downloads, with some particularly popular reports having over 20,000 downloads. 